\title{
Deletional Alpha-Thalassemia Alleles in Amazon Blood Donors
}

\author{
Fernanda Cozendey Anselmo, ${ }^{1,2}$ Natália Santos Ferreira, ${ }^{1,2}$ Adolfo José da Mota, ${ }^{3}$ \\ Marilda de Souza Gonçalves $\mathbb{D}^{4}{ }^{4}$ Sérgio Roberto Lopes Albuquerque, ${ }^{1}$ \\ Nelson Abrahim Fraiji, ${ }^{1}$ Ana Carla Dantas Ferreira, ${ }^{1,2}$ and José Pereira de Moura Neto $\mathbb{D}^{1,2}$ \\ ${ }^{1}$ Fundação Hospitalar de Hematologia e Hemoterapia do Amazonas, Manaus, Amazonas, Brazil \\ ${ }^{2}$ Universidade Federal do Amazonas, Faculdade de Ciências Farmacêuticas, Manaus, Amazonas, Brazil \\ ${ }^{3}$ Universidade Federal do Amazonas, Faculdade de Ciências Agrárias, Manaus, Amazonas, Brazil \\ ${ }^{4}$ Fundação Oswaldo Cruz-Centro de Pesquisas Gonçalo Moniz, Salvador, Bahia, Brazil
}

Correspondence should be addressed to José Pereira de Moura Neto; jpmn@ufam.edu.br

Received 17 January 2020; Accepted 22 February 2020; Published 14 April 2020

Academic Editor: Debra A. Hoppensteadt

Copyright (c) 2020 Fernanda Cozendey Anselmo et al. This is an open access article distributed under the Creative Commons Attribution License, which permits unrestricted use, distribution, and reproduction in any medium, provided the original work is properly cited.

\begin{abstract}
Alpha-thalassemia is highly prevalent in the plural society of Brazil and is a public health problem. There is limited knowledge on its accurate frequency and distribution in the Amazon region. Knowing the frequency of thalassemia and the prevalence of responsible mutations is, therefore, an important step in the understanding and control program. Hematological and molecular data, in addition to serum iron and serum ferritin, from 989 unrelated first-time blood donors from Amazonas Hemotherapy and Hematology Foundation (FHEMOAM) were collected. In this study, the subjects were screened for $-\alpha^{3.7 / 4.2} /^{20.5},{ }^{\mathrm{SEA}}{ }^{\mathrm{F}} \mathrm{FIL}$, and ${ }_{-}^{\text {MED }}$ deletions. Alpha-thalassemia screening was carried out between 2016 and 2017 among 714 (72.1\%) male and 275 (27.9\%) female donors. The aims of this analysis were to describe the distribution of various alpha-thalassemia alleles by gender, along with their genotypic interactions, and to illustrate the hematological changes associated with each phenotype. Amongst the patients, $5.35 \%(n=53)$ were diagnosed with deletion $-\alpha^{-3.7}$ and only one donor with $\alpha^{-4.2}$ deletion. From the individuals with $-\alpha^{-3.7}$, $85.8 \%(n=46)$ were heterozygous and $14.20 \%(n=7)$ were homozygous. The frequency of the $-\alpha^{-3.7}$ deletion was higher in male (5.89\%) than in female (4.0\%). There is no significant difference in the distribution of $-\alpha^{-3.7}$ by gender $(p=0.217)$. The $-\alpha^{20.5}$, ${ }^{\mathrm{SEA}}$, and $-{ }^{\mathrm{MED}}$ deletions were not found. All subjects were analyzed for serum iron and serum ferritin, with $1.04 \%$ being iron deficient $(n=5)$ and none with very high levels of stored iron $(>220 \mu \mathrm{g} / \mathrm{dL})$. Alpha-thalassemia- $2^{3.7 \mathrm{~kb}}$ deletion was the most common allele detected in Manaus blood donors, which is a consistent result, once it is the most common type of $\alpha$-thalassemia found throughout the world. As expected, the mean of hematological data was significantly lower in alpha-thalassemia carriers $(p<0.001)$, mainly homozygous genotype. Leukocytes and platelet count did not differ significantly. Due to the small number of individuals with iron deficiency found among blood donors, the differential diagnosis between the two types of anemia was not possible, even because minor changes were found among hematological parameters with iron deficiency and $\alpha$-thalassemia. Despite this, the study showed the values of hematological parameters, especially MCV and MCH, are lower in donors with iron deficiency, especially when associated with $\alpha$-thalassemia, and therefore, it may be useful to discriminate different types of microcytic anaemia. In conclusion, we believed screening for thalassemia trait should be included as part of a standard blood testing before blood donation. It should be noted that this was the first study to perform the screening for alpha deletions in blood donors from the Manaus region, and further studies are required to look at the effects of donated thalassemic blood.
\end{abstract}

\section{Introduction}

Thalassemias are the most common monogenic diseases prevalent worldwide. Thalassemias occur in high frequency in Italy, Middle East, India, and South and Southeast Asia.
The most common deletional thalassemia alleles are $-\alpha^{3.7}$, observed worldwide, and $-\alpha^{4.2}$, common in Asian countries [1-3].

Although many regions of the world still have no demonstrated data, current studies show about $7 \%$ of the 
world population have at least one hemoglobin disorder $[4,5]$.

The current Brazilian population was formed by successive migratory waves from the 16 th to 18 th centuries (Africans Slaves) and 19th and 20th centuries (Europeans). Many genetic studies over Brazilian population have been documented this heterogeneity with nonuniform European, African, and Amerindian pattern. Northern populations, generally, have higher African and Amerindians contributions when compared to other Brazilian regions [6-11].

Several laboratory tests may be used to detect and diagnose thalassemia, such as hemoglobin electrophoresis, complete blood count, blood smear, iron studies, and DNA analysis (genetic testing) [12].

Alpha-thalassemia carriers are asymptomatic and usually without hematologic abnormalities. Complications are mostly found in beta-thalassemia major and intermediate patients. In silent thalassemic state, carriers are essentially asymptomatic and the complete blood count, hemoglobin electrophoresis, and peripheral smear are usually normal. Slight hypochromia and microcytosis may be evident by microscopic evaluation [13-17].

Likewise, screening for thalassemia may help in providing blood and red blood cell concentrates with maximum functional capacity. In addition, detection of thalassemia in blood donors may reflect the spectrum of the disease in the population.

This is the first report in Manaus and Amazon regions that identifies thalassemia carriers among blood donors at the HEMOAM Foundation.

\section{Materials and Methods}

The studied population sample is composed of 989 first-time blood donors attending at FHEMOAM in Manaus, capital of the Amazonas State, Brazil, between 2016 and 2017. Only donors older than 18 years and, among these, individuals who claimed to be donating blood for the first time were invited to participated in this study.

Peripheral blood samples for the hematological analysis were obtained during a blood donation routine, $4 \mathrm{ml}$ volume in ethylenediaminetetraacetic acid (EDTA) and $4 \mathrm{ml}$ volume in no anticoagulant BD Vacutainer ${ }^{\circledR}$ blood collection tubes. The hematological investigations performed included a full blood count using the automated hematologic analyzer BC5800 (Mindray, Shenzhe, China); data have been obtained for the overall count of red blood cells (RBCs), concentration of hemoglobin $(\mathrm{Hgb})$, hematocrit (Hct), mean corpuscular volume (MCV), mean corpuscular hemoglobin $(\mathrm{MCH})$, mean corpuscular hemoglobin concentration (MCHC), red cell distribution width (RDW), total leukocytes, and platelet count. Iron and serum ferritin were measured as implemented in the automated A25 platform (BioSystems SA, Barcelona, Spain) using the Ferritin K081 kit (Bioclin) and Iron Serum K017 kit (Bioclin) [18, 19].
Genomic DNA was extracted from the peripheral blood using the HiYield Genomic DNA Extraction kit (BioAmerica Inc., USA). NanoDrop ND-1000 (Isogen Life Science, Netherlands) was used to measure DNA concentration according to the manufacturer's protocol.

All samples were tested to confirm the normal hemoglobin genotype “AA" using TaqMan ${ }^{\circledR}$ SNP Genotyping Assays (Applied Biosystems, Foster City, CA) on a StepOnePlus ${ }^{\mathrm{TM}} \quad$ Real-Time PCR System (Applied Biosystems).

PCR was performed as described previously [20] using the QIAGEN Multiplex PCR kit (1000 reactions; Cat no./ID 206143) with minor changes. In brief, PCR was performed using approximately $50 \mathrm{ng}$ of genomic DNA in $50 \mu \mathrm{L}$ reaction volumes containing $3 \mathrm{mM} \mathrm{MgCl}_{2} ; 5 \mathrm{x}$ Q-Solution and $0.35 \mu \mathrm{mol} / \mathrm{L}$ of each primer (Table 1 ), including primers that act as internal controls; $250 \mu \mathrm{mol} / \mathrm{L}$ DNTPs; $2.5 \mathrm{U}$ of Taq polymerase (Qiagen); and RNase-free water (q.s.p). The cycling was performed using $1100^{\circledR}$ gradient Thermal Cycler (Bio-Rad, Hercules, California, USA) with an initial 10 minutes hold at $96^{\circ} \mathrm{C}$, followed by 34 cycles at $96^{\circ} \mathrm{C}$ for 45 seconds, $60^{\circ} \mathrm{C}$ for 45 seconds, and $72^{\circ} \mathrm{C}$ for 150 seconds and a final extension at $72^{\circ} \mathrm{C}$ for 10 minutes.

Descriptive statistics were used to hematological data, iron and ferritin status. Differences in continuous variables between two groups were analyzed using the Student $t$ test or Mann-Whitney test for Gaussian and non-Gaussian distributed variables, respectively. One-way ANOVA was performed to calculate the average and standard deviation. A $p$ value less than or equal to 0.05 was considered statistically significant. All statistical analyses were performed using the GraphPad Prism Software v. 5.0 (GraphPad Prism Software Inc., San Diego, California, USA) and SPSS version 19.

\section{Results and Discussion}

Blood samples from 989 first-time donors, 714 (72.1\%) males and $275(27.9 \%)$ females, were analyzed, and 53 of them (5.35\%) were positive to $-\alpha^{3.7}$ deletion. The $-\alpha^{4.2}$ deletion was detected in only one subject. No subjects with $-\alpha^{20.5}$, - ${ }^{\text {SEA }}$, and - ${ }^{\text {MED }}$ deletions were found, suggesting the probable presence of "rare" $\alpha$-thalassemia genotypes in the Amazon region to be as in other Brazilian populations. The results are summarized in Table 2 .

The $\alpha$-thalassemia alleles frequency found from the random blood donors' samples is similar to that estimated in other studies from Brazilian population (average among 2.5-8\%). Our study showed lower $\alpha$-thalassemia frequency when compared to $14.89 \%$ reported in the Uberaba Regional Blood Center's (Hemominas Foundation, Uberaba, Brazil) work, with all cases being heterozygous for the $-a^{3.7}$ deletion [21-23].

This frequency is probably underestimated since the blood donors are generally healthier and therefore have hematological data with values equal to or above normal reference values when compared to attending population at 
TABle 1: Primers used for detection of common deletional determinants of alpha-thalassemia.

\begin{tabular}{lrl}
\hline Primer code & $5^{\prime}-3^{\prime}$ sequence & Fragment size (base pairs) \\
\hline LIS1-F & G T C G T C A C T G G C A G C G T A G A T C & \\
LIS1-R & G A T T C C A G G T T G T A G A C G G A C T G & $\sim 2503$ \\
$\alpha 2^{3.7} \mathrm{~F}$ & C C C C T C G C C A A G T C C A C C C \\
$\alpha 2 \mathrm{R}$ & A G A C C A G G A A G G G C C G G T G \\
$\alpha 2^{3.7} \mathrm{~F}$ & C C C C T C G C C A A G T C C A C C C & $\sim 2022$ \\
${ }_{3.7 / 20.5} \mathrm{R}$ & A A A G C A C T C T A G G G T C C A G C G \\
SEA-F & C G A T C T G G G C T C T G T G T T C T C & $\sim 1800$ \\
SEA-R & A G C C C A C G T T G T G T T C A T G G C \\
${ }^{4.2} \mathrm{~F}$ & G G T T T A C C C A T G T G G T G C C T C & $\sim 1350$ \\
${ }^{4.2} \mathrm{R}$ & C C C G T T G G A T C T T C T C A T T T C C C & $\sim$ \\
${ }^{20.5} \mathrm{~F}$ & G C C C A A C A T C C G G A G T A C A T G & $\sim 1630$ \\
${ }^{3.7 / 20.5} \mathrm{R}$ & A A A G C A C T C T A G G G T C C A G C G & \\
FIL-F & T G C A A A T A T G T T T C T C T C A T T C T G TG & $\sim 1000$ \\
FIL-R & A T A A C C T T T A T C T G C C A C A T G T A G C \\
MED-F & T A C C C T T T G C A A G C A C A C G T A C & $\sim 1170$ \\
MED-R & T C A A T C T C C G A C A G C T C C G A C & $\sim 807$ \\
\hline
\end{tabular}

TABLE 2: Overall alpha-thalassemia genotypes among the first-time blood donors from FHEMOAM (2016-2017)

\begin{tabular}{lccccr}
\hline \multirow{2}{*}{ Gender } & & \multicolumn{3}{c}{$\alpha$-Globin genotypes } & Total \\
& $\alpha \alpha / \alpha \alpha$ & $-\alpha^{3.7} / \alpha \alpha$ & $\alpha^{3.7} / \alpha^{3.7}$ & $-\alpha^{4.2}$ & -MED, -FIL, SEA, 20.5 \\
\hline Male (\%) & $671(93.9)$ & $37(5.2)$ & $05(0.7)$ & $01(0.1)$ & - \\
Female (\%) & $264(96.0)$ & $9(3.3)$ & $02(0.7)$ & - & - \\
Total (\%) & $935(94.4)$ & $46(4.7)$ & $07(0.7)$ & $01(0.1)$ & - \\
\hline
\end{tabular}

health posts and hospitals, even for normal patients without clinical manifestations.

As expected, the mean of hematological data was significantly lower in $\alpha$-thalassemia carriers $(p<0.001)$. Leukocytes and platelet count did not differ significantly (Table 3). On comparing hematological parameters, independent of gender, there was a most pronounced microcytosis in the cases with homozygous genotype. Microcytosis was found in all homozygous cases, but it is also important to note that normal RBC indices do not rule out $\alpha$-thalassemia carrier [24]. Our results corroborate the national and international reported data, i.e., alpha-thalassemia, mainly the $-\alpha^{3.7}$ deletion as one of the main causes of microcytosis and mild or severe hypochromia in individuals without anemia. These results have high impact in the clinic medicine, since these hematological data are often interpreted as indicators of iron deficiency $[25,26]$.

We propose $\alpha$-thalassemia as a common cause of microcytosis, given the high proportion (42.2\%) of the microcytic blood donors carrying $-\alpha^{3.7}$ deletions. Randomly, 479 subjects were analyzed to test iron and ferritin. The results showed only $1.04 \%$ has iron deficiency $(n=5)$ and very high levels of stored iron $(>220 \mu \mathrm{g} / \mathrm{dL})$ were not observed. Microcytic hypochromic anemia is a common hematological abnormality, and it is usually caused by iron deficiency and/or thalassemia, usually $\alpha$ genes deletion. Our results point out to the importance of investigating $\alpha$-thalassemia, besides serum iron levels, to prevent medical intervention and iron therapy unnecessary in subjects with microcytic anemia due to thalassemia [27-29].
Serum iron and ferritin dosages are good indicators of iron storage, enabling the early detection of iron deficiency. Nonetheless, in cases where ferritin levels are within the reference values or increased, other tests such as total iron binding capacity and transferrin saturation may help in better characterization of the type of anemia $[30,31]$.

In blood banks from Brazil, although there are rigid and regulated techniques, it is still a great problem to enhance the identification of all types and causes of anemia. This is due to the need to use different methodologies in the differential diagnosis [16]. However, several studies have shown good results using hematological parameters of the conventional hemogram [32, 33].

Another interesting finding was the tendency of red cell volume distribution width (RDW) elevation proportionally to the loss of the alpha genes, corroborating with other studies in the literature. The thalassemia patients have smaller and more homogeneous erythrocytes (mainly microcytic), which leads us to correlate high RDW in iron deficiency than in thalassemia [34-36].

We understand the difficulty in screening for alphathalassemia genotypes, especially for the final diagnosis, it is necessary to include a technique that is currently expensive and with few people qualified for it. However, we consider that molecular techniques should be included as part of standard blood tests before blood donation. We even think that national policies should be reformulated to select the blood used for healthy transfusion and with no risk. 


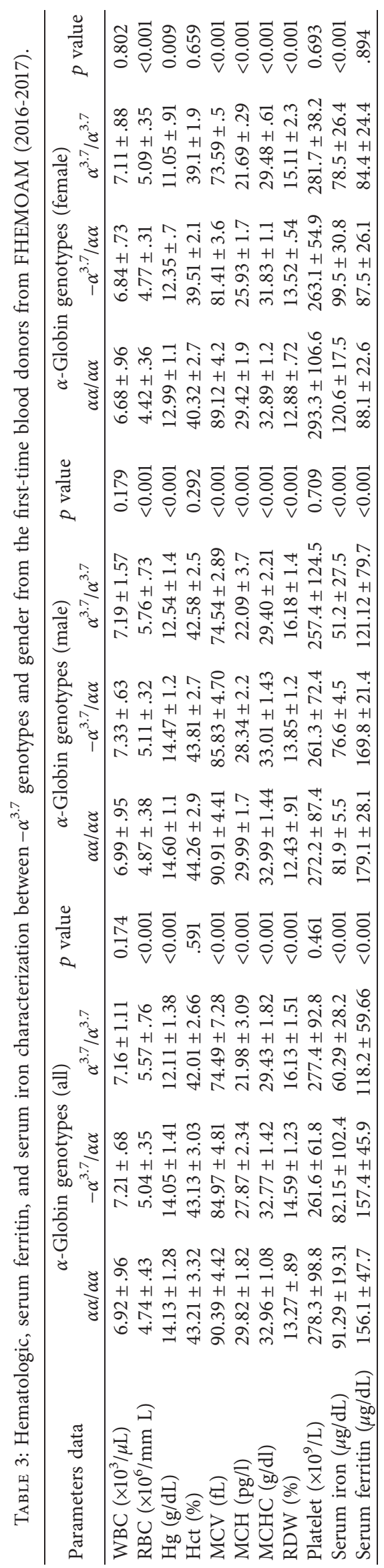




\section{Data Availability}

The data used to support the findings of this study may be released upon application to the corresponding author via email (jp-mn@hotmail.com).

\section{Disclosure}

The sponsors of this study are public or nonprofit organizations that support science in general. They had no role in gathering, analyzing, or interpreting the data.

\section{Conflicts of Interest}

The authors declare no conflicts of interest.

\section{Acknowledgments}

The authors wish to thank all blood donors of the FHEMOAM for contributing and participating in this study. Also, the authors thank the staff of the Molecular Biology Laboratory of the Federal University of Amazonas (UFAM) and Gonçalo Moniz Institute (IGM) (FIOCRUZ/BAHIA) for the technical support. Finally, they also thank the (Fundação de Amparo a Pesquisa do Estado do Amazonas) (FAPEAM) (Processo: 1094/2013-FAPEAM) for the financial support..

\section{References}

[1] J. Flint, R. M. Harding, J. B. Boyce, and J. B. Clegg, "8 the population genetics of the haemoglobinopathies," Baillière's Clinical Haematology, vol. 6, no. 1, pp. 215-262, 1993.

[2] P. John, J. P. Greer, D. A. Arber, B. Glader et al., Wintrobe's Clinical Hematology, Lippincott Williams \& Wilkins Company, Philadelphia, PA, USA, 2013.

[3] M. Murtaza, A. Thiru, E. M. IIIzam et al., "Pathophysiology, clinical manifestations, and carrier detection in Thalassemia," IOSR Journal of Dental and Medical Sciences, vol. 15, no. 11, pp. 122-126, 2016.

[4] A. Cao and R. Galanello, "Beta-thalassemia," Genetics in Medicine, vol. 12, no. 2, pp. 61-76, 2010.

[5] G. Modiano, G. Morpugo, L. Terrenato, and etal, "Protection against malaria morbidity: near-fixation of the alpha thalassemia in a Nepalese population," American Journal of Human Genetics, vol. 48, no. 2, pp. 390-397, 1991.

[6] F. M. Salzano and M. C. Bortolini, The Evolution and Genetics of Latin American Populations, p. 512, Cambridge University Press, Cambridge, UK, 2002.

[7] S. M. Callegari-Jacques, D. Grattapaglia, F. M. Salzano et al., "Historical genetics: spatiotemporal analysis of the formation of the Brazilian population," American Journal of Human Biology, vol. 15, no. 6, pp. 824-834, 2003.

[8] V. M. Zembrzuski, M. H. Callegari-Jacques, and M. H. Hutz, "Application of an African Ancestry Index as a genomic control approach in a Brazilian population," Annals of Human Genetics, vol. 70, no. 6, pp. 822-828, 2006.

[9] F. P. N. Leite, S. E. B. Santos, E. M. R. Rodríguez et al., "Linkage disequilibrium patterns and genetic structure of Amerindian and non-Amerindian Brazilian populations revealed by long-range X-STR markers," American Journal of Physical Anthropology, vol. 139, no. 3, pp. 404-412, 2009.
[10] H. Moura, As Migrações na Região Norte em Período Recente: Uma Abordagem Preliminar, IESAM/Fundação Joaquim Nabuco, Manaus, Brazil, 1998.

[11] O. I. Márcia de, Levantamento de Dados Sobre a Realidade Migratória, Pastoral do Migrante, Manaus, Brazil, 2000.

[12] How are Thalassemia Diagnosed?, Vol. 3, NHLBI, Bethesda, MD, USA, 2012.

[13] H. Satwani, J. Raza, M. Alam, and A. Kidwai, "Previous studies from various regions of the Brazil have reported considerable prevalence's in blood donors. However, such blood is considered suitable for blood transfusion when its hemoglobin level falls within the normal range. Endocrine complications in thalassemias; frequency and association with ferritin levels," Public Philosophy Journal, vol. 29, no. 2, pp. 113-119, 2005.

[14] D. J. Weatherall and J. B. Clegg, The Thalassaemia Syndromes, Blackwell Science, Oxford, UK, 4th edition, 2001.

[15] M. A. Zago, F. Costa, C. A. S. Tone, and C. Bottura, "Hereditary hemoglobin disorders in a Brazilian population," Human Heredity, vol. 33, no. 2, pp. 125-129, 1983.

[16] E. M. Kimura, D. M. Oliveira, S. E. Jorge et al., "Investigating alpha-globin structural variants: a retrospective review of 135,000 Brazilian individuals," Revista Brasileira de Hematologia e Hemoterapia, vol. 37, no. 2, pp. 103-108, 2015.

[17] L. A. S. Nunes, H. Z. W. Grotto, R. Brenzikofer et al., "Hematological and biochemical markers of iron status in a male, young, physically active population," BioMed Research International, vol. 2014, Article ID 349182, 7 pages, 2014.

[18] A. M. Moghadam, M. M. Natanzi, M. Djalali et al., "Relationship between blood donors' iron status and their age, body mass index and donation frequency," Sao Paulo Medical Journal, vol. 131, no. 6, pp. 377-383, 2013.

[19] F. A. Noor Haslina, R. Rosline, A. W. Zaidah, M. N. au, fnm Marini, and M. Y. Shafini, "Detection of common deletional alpha-thalassemia spectrum by molecular technique in Kelantan, northeastern Malaysia," ISRN Hematology, vol. 2012, pp. 1-3, 2012.

[20] S. S. Chong, C. D. Boehm, D. R. Higgs et al., "A rapid and reliable 7-deletion multiplex polymerase chain reaction assay for $\alpha$-thalassemia," Blood, vol. 98, no. 1, pp. 250-251, 2001.

[21] A. E. S. Souza, G. L. Cardoso, S. Y. L. Takanashi, and J. F. Guerreiro, " $\alpha$-Thalassemia (3.7 kb deletion) in a population from the Brazilian Amazon region: santarém, pará state," Genetics and Molecular Research, vol. 8, no. 2, pp. 477-481, 2009.

[22] R. A. V. d. Souza, A. M. Carlos, B. M. B. d. Souza, C. V. Rodrigues, G. d. A. Pereira, and H. Moraes-Souza, " $\alpha$-Thalassemia: genotypic profile Associated with ethnicity and hematological differentiation of iron deficiency anemia in the region of Uberaba, minas gerais, Brazil," Hemoglobin, vol. 39, no. 4, pp. 264-269, 2015.

[23] J. S. Carneiro, M. S. Goncalves, S. R. L. Albuquerque, N. A. Fraiji, and J. P. Moura Neto, "Beta-globin haplotypes and alpha-thalassemia $3.7 \mathrm{~kb}$ deletion in sickle cell disease patients from the occidental Brazilian Amazon," Journal of Hematology, vol. 5, no. 4, pp. 123-128, 2016.

[24] D. Higgs, M. Vickers, A. Wilkie, I. Pretorius, A. Jarman, and D. Weatherall, "A review of the molecular genetics of the human alpha-globin gene cluster," Blood, vol. 73, no. 5, pp. 1081-1104, 1989.

[25] M. Sharma, S. Pandey, R. Ranjan, T. Seth, and R. Saxena, "Prevalence of alpha thalassemia in microcytic anemia: a tertiary care experience from north India," Mediterranean 
Journal of Hematology and Infectious Diseases, vol. 7, no. 1, 2015.

[26] E. Borges, M. R. S. C. Wenning, E. M. Kimura, S. A. Gervásio, F. F. Costa, and M. F. Sonati, "High prevalence of a thalassemia among individuals with microcytosis and hypochromia without anemia," Brazilian Journal of Medical and Biological Research, vol. 34, pp. 759-762, 2001.

[27] M. 1 Ali and J. Lafferty, "The clinical significance of hemoglobinopathies in the Hamilton region: a twenty-year review," Clinical and Investigative Medicine, vol. 15, no. 5, pp. 401-405, 1992.

[28] R. Origa and P Moi, GeneReviews ${ }^{\circledR}$ [Internet], M. P. Adam, H. H. Ardinger, R. A Pagon et al., Eds., University of Washington, Seattle, WA, USA, 1993.

[29] P. Winichagoon, R. Kumbunlue, P. Sirankapracha, P. Boonmongkol, and S. Fucharoen, "Discrimination of various thalassemia syndromes and iron deficiency and utilization of reticulocyte measurements in monitoring response to iron therapy," Blood Cells, Molecules, and Diseases, vol. 54, no. 4, pp. 336-341, 2015 Apr.

[30] J. F. Matos, L. M. S. Dusse, K. B. G. Borges, R. L. V. de Castro, W. Coura-Vital, and M. d. G. Carvalho, "A new index to discriminate between iron deficiency anemia and thalassemia trait," Revista Brasileira de Hematologia e Hemoterapia, vol. 38, no. 3, pp. 214-219, 2016.

[31] M. T. Jalali, A. Mohseni, B. Keikhaei et al., "Evaluation of diagnostic efficacy of serum sTfR assay in iron-deficiency anemia and beta-thalassemia trait in Shafa hospital, Ahvaz, Iran 2010," European Review for Medical and Pharmacological Sciences, vol. 16, no. 10, pp. 1441-1445, 2012.

[32] Brasil. Ministério da Saúde. Agência Nacional de Vigilância Sanitária. Resolução RDC n 34, de 29 de maio de 2014. Determina o Regulamento Técnico para os procedimentos hemoterápicos. [Internet] Brasília: Ministério da Saúde; 2014 http://bvsms.saude.gov.br/bvs/saudelegis/anvisa/.2014/ rdc0034_11_06_2014.pdf.

[33] P. C. Giordano, "Strategies for basic laboratory diagnostics of the hemoglobinopathies in multi-ethnic societies: interpretation of results and pitfalls," International Journal of Laboratory Hematology, vol. 35, no. 5, pp. 465-479, 2013.

[34] T. A. Jameel, M. Baig, I. Ahmed, M. B. Hussain, and M. B. Doghaim Alkhamaly, "Differentiation of beta thalassemia trait from iron deficiency anemia by hematological indices," Pakistan Journal of Medical Sciences, vol. 33, no. 3, pp. 665-669, 2017.

[35] D. Velasco-Rodríguez, C. Blas, J.-M. Alonso-Domínguez et al., "Cut-off values of hematologic parameters to predict the number of alpha genes deleted in subjects with deletional alpha thalassemia," International Journal of Molecular Sciences, vol. 18, no. 12, p. 2707, 2017.

[36] G. Aydogan, S. Keskin, F. Akici et al., "Causes of hypochromic microcytic anemia in children and evaluation of laboratory parameters in the differentiation," Journal of Pediatric Hematology/Oncology, vol. 41, no. 4, pp. e221-e223, 2019. 